\title{
Prediction of the Heat Release Rate of Douglas Fir
}

\author{
WILLIAM J. PARKER \\ Center for Fire Research \\ National Bureau of Standards' \\ Gaithersburg, Maryland 20899, USA
}

\section{ABSTRACT}

Measurements have been made on the thermal diffusivity of Douglas fir and its char up to $550^{\circ} \mathrm{C}$. Its char contraction factors have also been determined. Interpretation of some data in the literature has resulted in the establishment of the specific heat as a function of temperature over this range. These thermophysical property data along with some data reported separately on the thermochemical properties of cellulose, mannan, xylan and lignin were used as input to a model for the heat release rate of wood in order to calculate the heat release rate and heat of combustion of Douglas fir exposed to an external radiant flux of $25 \mathrm{~kW} / \mathrm{m}^{2}$. These calculations were compared with measurements made in the Cone calorimeter. The agreement is reasonable at this stage of the model development.

Key Words: Wood, Heat Release Rate, Thermal Diffusivity, Specific Heat, Heat of Combustion and Char Contraction

\section{INTRODUGTION}

A model for the heat release rate of wood which takes char contraction and the properties of the individual chemical components of wood into account has been described previously [1]. It was an extension of an earlier model for the mass loss rate of wood presented by Atreya [2]. The heat release rate model was originally tested on Douglas fir particle board assuming that the wood contained only a single chemical component whose pyrolysis was governed by a single first order reaction [1]. This was necessary because of the lack of input property data. Since then an apparatus was developed for determining the kinetic parameters and the heat of combustion of the volatiles under conditions similar to those in the interior of a flaming slab of wood [3]. Data have been obtained on each of the four major chemical components present in Douglas fir using this apparatus [4]. Thermal diffusivity measurements on Douglas fir and its char are described in the present paper along with the determination of the char contraction factors. Using these data and the thermochemical property data for the individual components, calculations of the heat release rate and heat of combustion are presented for a vertical slab of wood under a constant external

${ }^{1}$ Contribution from the National Bureau of Standards, not subject to copyright. 
radiant flux of $25 \mathrm{~kW} / \mathrm{m}^{2}$. These calculations are compared with measurements in the cone calorimeter [5]. The model includes cooling by the volatiles on their way to the front surface, but does not provide for flow toward the rear surface. It also does not account for char oxidation at the surface or for reactions between the char and the volatiles passing through it.

\section{MATERTAL}

Douglas-fir heartwood was used for this investigation. The material was obtained from a local lumber yard and analyzed at the Forest Products Laboratory [4] to determine its chemical composition and to verify that it did not contain reaction wood. It was composed of 348 cellulose, $30 \%$ lignin, $21 \%$ mannan, 78 xylan and $8 \%$ extractable materials. Since the effect of the extractable materials has not yet been included in the model, the composition was assumed to be $37 \%$ cellulose, $23 \%$ mannan, $7 \%$ xylan and $33 \%$ 1ignin based on the composition of the extracted wood. The calculations and measurements reported in this paper are for oven-dry wood which had a density of $500 \mathrm{~kg} / \mathrm{m}^{2}$.

\section{THERMOCHEMICAL PROPERTIES}

The thermochemical properties needed by the model include the kinetic parameters which describe the mass loss rate, the heat of combustion of the volatile pyrolysis products, and the heat of pyrolysis. These are needed for each of the chemical components that make up the wood. In general these properties are a function of the mass retention fraction ( $Z$ ) and the temperature (T). The mass retention fraction is the mass of an element divided by its original mass. The combination of pyrolyzer and catalytic converter (PYROCAT) used for making the measurements of the heat of combustion of the volatiles and the kinetic parameters has been described [3] while the measurements on the four major chemical components of Douglas-fir have been reported [4] and are presented in Table 1. The pre-exponential factor (A) and the activation energy ( $E$ ) are empirically determined parameters which depend on $Z$ and $T$ and account for the fractional mass loss rate according to the formula,

$\mathrm{dZ} / \mathrm{dt}=-A \exp [-\mathrm{E} /(\mathrm{R}(\mathrm{T}+273))]$.

Not much physical significance should be attached to such parameters for these complex materials.

TABLE 1. Thermochemical Properties Used in the Model Calculations

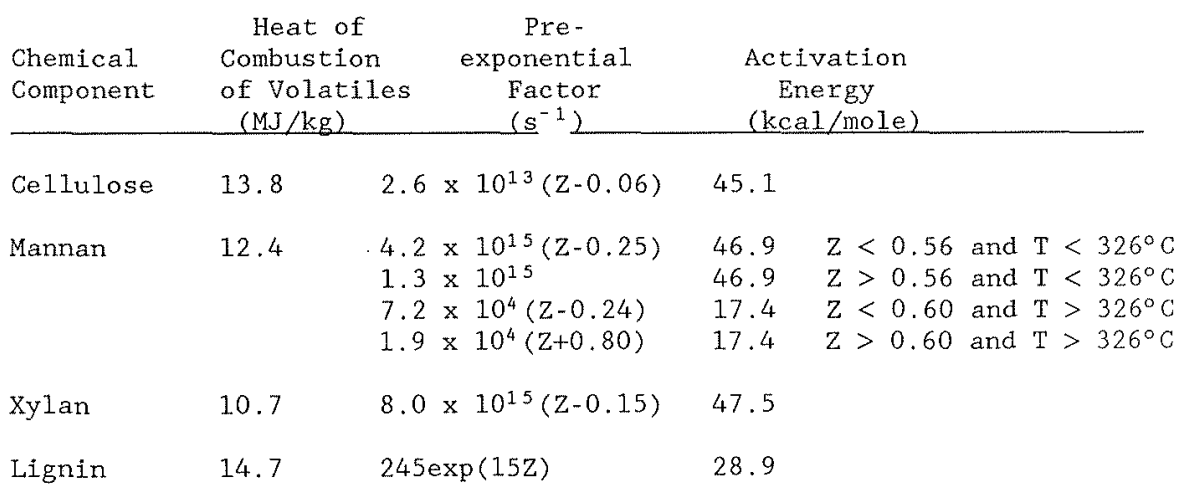


The heat of pyrolysis was assumed to be zero as discussed below.

\section{THERMOPHYSICAL PROPERTIES}

The thermophysical properties needed by the model are the specific heat, thermal diffusivity, char contraction factors, original density, absorptivity and the emissivity. The thermal conductivity which also appears in the model is equal to the product of the specific heat, density and thermal diffusivity. The density at any time is equal to the original density multiplied by the mass retention fraction and divided by the char contraction factors in the three directions. The char contraction factors are the dimensions of an element divided by its original dimensions.

\section{Specific Heat}

The specific heat of wood depends on the temperature and moisture content but is practically independent of density or species. Dunlap [6] determined the temperature dependence of the specific heat of oven-dry wood up to $106^{\circ} \mathrm{C}$ for 20 different species. His formula is given by

$\mathrm{C}_{\mathrm{w}}=1.11+0.00486 \mathrm{~T} \mathrm{~kJ} / \mathrm{kg}-\mathrm{K}$.

Koch [7] found that

$\mathrm{C}_{\mathrm{w}}=1.11+0.0042 \mathrm{~T} \mathrm{~kJ} / \mathrm{kg}-\mathrm{K}$

for oven-dry spruce pine between $60^{\circ} \mathrm{C}$ and $140^{\circ} \mathrm{C}$ where $\mathrm{T}$ is in ${ }^{\circ} \mathrm{C}$.

The specific heat of charcoal is reported by Dunlap to be $0.67 \mathrm{~kJ} / \mathrm{kg}-\mathrm{K}$ (8). The specific heat of the final char is assumed to be the same as that of carbon as given in the Handbook of Chemistry and Physics [8]. Expressed in SI units, this is given by

$\mathrm{C}_{\mathrm{c}}=1.43+3.55 \times 10^{-4}(\mathrm{~T}+273)-7.32 \times 10^{4} /(\mathrm{T}+273)^{2} \mathrm{~kJ} / \mathrm{kg}-\mathrm{K}$.

This formula yields a value of $0.68 \mathrm{~kJ} / \mathrm{kg}-\mathrm{K}$ at $20^{\circ} \mathrm{C}$. In calculating the specific heat of the partially charred wood, it was assumed that each element is composed of a mixture of virgin wood of specific heat, $C_{w}$, and fully charred wood of specific heat, $C_{c}$. With this assumption the specific heat can be shown to be given by

$\mathrm{C}=\mathrm{C}_{\mathrm{w}}\left(\mathrm{Z}-\mathrm{Z}_{\mathrm{f}}\right) /\left(\left(1-\mathrm{Z}_{\mathrm{f}}\right) \mathrm{Z}\right)+\mathrm{C}_{\mathrm{c}} \mathrm{Z}_{\mathrm{f}}(1-\mathrm{Z}) /\left(\left(1-\mathrm{Z}_{\mathrm{f}}\right) \mathrm{Z}\right)$

for oven-dry partially charred wood during the transition from virgin wood to final char.

Susott [9] measured the heat of pre-ignition for three woody fuels using differential scanning calorimetry (DSC) and thermogravimetric analysis (TGA). His paper shows a comparison of the DSC and the differentiated TGA results for a mixture taken from pine and fir lumber. Susott tabulated the integrated heat input along with the mass retention fraction for this mixture. Figure 1 shows the integrated heat input reported in that table compared to the enthalpy increase in the solid wood determined by the integration of equation 5 for specific heat. Initially equations 3 and 4 were substituted into equation 5 for the specific heat of virgin wood and wood char respectively. However, a 
betcer fit to the data was obtained over the full temperature range of concern by using a slightly lower temperature coefficient for virgin wood. Therefore, the following equation was finally used for $\mathrm{C}_{\mathrm{w}}$ :

$C_{\mathrm{w}}=1.11+0.0037 \mathrm{~T} \mathrm{~kJ} / \mathrm{kg}-\mathrm{K}$.

Equations 4, 6 and 5 provide a general expression for the specific heat of wood and wood char as a function of temperature as it progresses from it's virgin state to its final char.

An interesting feature of figure 1 is that equation 5 fits well into the region of significant mass loss (approximately 50\%). If the equations are correct in this region it means that the heat of pyrolysis there is quite 1ow. As the mass continues to drop, the wood becomes endothermic as indicated by the separation of the two curves. This is followed by a period of nearly equal exothermicity with a net overall heat of pyrolysis close to zero as indicated by the joining of the two curves again just below $500^{\circ} \mathrm{C}$. Based on this interpretation of Susott's data the heat of pyrolysis of wood is taken to be zero as was done in Atreya's model [2].

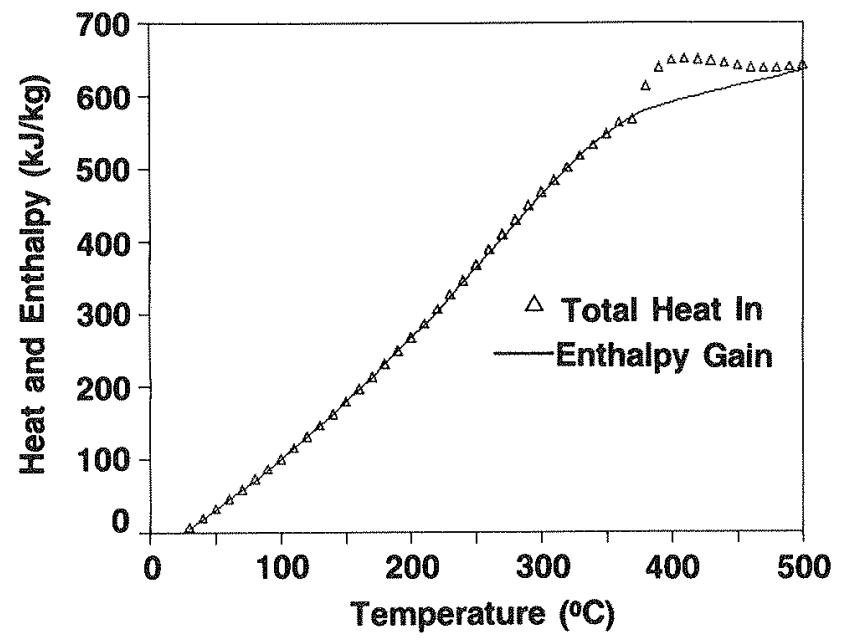

FIGURE 1. Heat in and enthalpy gain of wood specimen.

Therma1 Diffusivity

A method of measuring the thermal diffusivity of wood and wood char over the temperature range from room temperature up to $550^{\circ} \mathrm{C}$ was devised. Two sample pieces on the order of $50 \mathrm{~mm}$ by $50 \mathrm{~mm}$ by $5 \mathrm{~mm}$ thick axe placed together to form a $10 \mathrm{~mm}$ thick specimen with an interior $5 \mathrm{mil}$ thermocouple at its midpoint. The temperature of the surface on each side of the specimen is also monitored with a 5 mil thermocouple. The specimen is placed in a glass tube located in a high temperature tube furnace. A purge rate of $15 \mathrm{ml} / \mathrm{s}$ of nitrogen is introduced into the glass tube to protect the specimen from oxidation. The furnace is turned 
on after the assembly is in place. The furnace power setting is continuously adjusted so that the rate of temperature rise of the specimen is of the order of 2 degrees $C$ per minute. There is a lag of the order of 2 to 5 degrees between the center tempexature and the average of the two exterior surface temperatures. These three temperatures are recorded and later used to calculate the thermal diffusivity according to the equation which will now be derived.

Carslaw and Jaeger [10] present the following solution for the temperature distribution in a slab of thickness, $l$, constant thermal diffusivity, $\alpha$, surface temperature histories, $T(0, t)$ and $T(\ell, t)$ and whose inftial temperature distribution is $f(x)$ :

$$
\begin{aligned}
& T(x, t)=\frac{2}{\ell} \sum_{n=1}^{\infty} \exp \left(-n^{2} \pi^{2} \alpha t / \ell^{2}\right) \sin (n \pi x / \ell)\left[\int_{0}^{\ell} f\left(x^{\prime}\right) \sin \left(n \pi x^{\prime} / \ell\right) d x^{\prime}\right. \\
& \left.+(n \pi \alpha / \ell) \int_{0}^{t} \exp \left(n^{2} \pi^{2} \alpha \lambda / \ell^{2}\right)\left(T(0, \lambda)-(-1)^{n} T(l, \lambda)\right) d \lambda\right]
\end{aligned}
$$

Setting the initial temperature distribution equal to zero and performing successive integration by parts on the second integral, the temperature at the midplane can be shown to be

$\mathrm{T}_{\mathrm{M}}(t)=\theta(t)-0.125 \ell^{2}(\mathrm{~d} \theta / \mathrm{d} t) / \alpha+0.013 \ell^{4}\left(\mathrm{~d}^{2} \theta / d t^{2}\right) / \alpha^{2}+\ldots$

where $\theta=(T(0, t)+T(l, t)) / 2$

This series was found to converge. Keeping only the first three terms of the series, equation 8 can be rearranged to give the themal diffusivity as

$\alpha=\left(0.125 \ell^{2} \theta(t) / W\right)\left(1+(1-y)^{\frac{1}{2}}\right)$

where

$W=\theta(t)-T_{M}(t) \quad$ and $\quad y=3.33 W\left(d^{2} \theta / d t^{2}\right) /(d \theta / d t)^{2}$

Equation 9 can also be shown to hold for a variable thermal diffusivity provided that

$\mathrm{d} \alpha / \mathrm{dT} \ll \alpha / \ell^{2} \mathrm{~d} \theta / \mathrm{dt}$

Equation 9 was used to calculate the thermal diffusivity from the recorded temperature data. The $y$ term was small enough to neglect in all of the tests that were conducted. It is assumed that no error was incurred by dropping the higher order terms. Also the above treatment assumes that the slab is inert.

This method for measuring the thermal diffusivity has the following advantages: (1) One dimensional heat transfer which is important because of the variation in thermal conductivity with grain orientation, (2) A sufficient specimen thickness to average out some of the heterogeneity inherent in wood, (3) The ability to generate thermal diffusivity data over a wide temperature range on a single test run, and (4) Low cost. A rigorous analysis of the accuracy of the method and an optima1. engineering design, however, have yet to be done. 


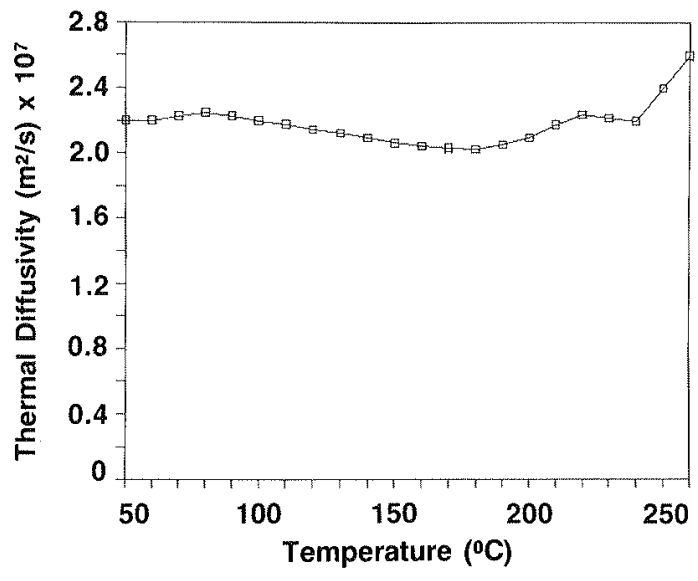

FIGURE 2. Thermal diffusivity of Douglas fir as a function of temperature.

Figure 2 shows the measured thermal diffusivity of a Douglas fir specimen as a function of temperature determined on a single run. It is relatively independent of temperature. The increase above $240^{\circ} \mathrm{C}$ is probably due to decomposition reactions starting to occur in the wood. In order to determine the thermal diffusivity of the char by this method it is first necessary to diminish the rate of these reactions to a very low level by pre-charring the specimen at some temperature above the range of the measurements until the rate of mass loss becomes

negligeable. A series of measurements made on the char between $250^{\circ} \mathrm{C}$ and $550^{\circ} \mathrm{C}$ yielded an average value of $2.3 \times 10^{-7} \mathrm{~m}^{2} / \mathrm{s}$ with a variation within 20\%. for mass retention fractions above 0.3 . For mass retention fractions below 0.3 the thermal diffusivity increases strongly at all temperatures. For specimens pre-charred at $600^{\circ} \mathrm{C}$ and above, the mass retention fraction was always below 0.3 . The thermal diffusivity as a function of mass retention fraction and temperature has not yet been documented in this region. Tye [11] found a strong increase in the thermal diffusivity of pittsburgh seam coal which had been previously heated above $600^{\circ} \mathrm{C}$ and has shown that its thermal diffusivity depends on the highest temperature to which it has been previously heated and has 1ittle dependence on the temperature at which it is measured. Relating that to the wood char it may turn out that the thermal diffusivity is principally a function of the mass retention fraction. Evans and Emmons [12] deduced the thermal diffusivity of charcoal from burning rate experiments on basswood charcoal cylinders. They found a value of $2.6 \mathrm{x}$ $10^{-7} \mathrm{~m}^{2} / \mathrm{s}$ from 100 to $1000^{\circ} \mathrm{C}$. There are obvious structural differences between coal, commercially produced charcoal and the char formed during high temperature pyrolysis of wood. Yet the thermal diffusivity below $550^{\circ} \mathrm{C}$ is similar for all three materials. 
A universal formula for the thermal conductivity of wood (nomal to the grain) at room temperature as a function of specific gravity and moisture content was established experimentally by Maclean [13]. This is given by

$\mathrm{K}=[0.237+2.00 \mathrm{~S}(1+.020 \mathrm{M})] \times 10^{-4} \mathrm{~kW} / \mathrm{m}-\mathrm{K}$.

This formula holds over a specific gravity (S) range for wood of 0.3 to 0.8 and a moisture content (M) range of 0 to 408 . Using this formula for the thermal conductivity and equation 6 for specific heat, the thermal diffusivity of oven-dry Douglas fir at ambient temperature was calculated to be $2.1 \times 10^{-7} \mathrm{~m}^{2} / \mathrm{s}$. Measurements of the thermal conductivity of Douglas fir from the same board stock were made with a guarcied hot plate at $25^{\circ} \mathrm{C}, 101^{\circ} \mathrm{C}$ and $151^{\circ} \mathrm{C}$. These yielded values of $1.12 \times 10^{-4}$, $1.45 \times 10^{-4}$ and $1.65 \times 10^{-4} \mathrm{~kW} / \mathrm{m}-\mathrm{K}$ respectively. The associated thermal diffusivities were calculated to be $1.86 \times 10^{-7}, 1.95 \times 10^{-7}$ and $1.98 \mathrm{x}$ $10^{-7} \mathrm{~m}^{2} / \mathrm{s}$. These values are close to those for the thermal diffusivity measured directly. These data provide limited validation for the thermal diffusivity measuring technique described above.

The thermal diffusivity used in the model calculations was chosen to be $2.1 \times 10^{-7} \mathrm{~m}^{2} / \mathrm{s}$ based on the thermal conductivity and specific heat calculations and is assumed to be constant over the entire temperature and mass retention fraction range. This can lead to errors in the calculations at high incident heat fluxes when a substantial portion of the char layer exceeds $600^{\circ} \mathrm{C}$. By incorporating equation 11 into the model the thermal diffusivity can be calculated for woods of different densities.

\section{Char Contraction}

As the pyrolysis proceeds, the char that is formed contracts and ultimately approaches a graphitic structure. Measurements of char contraction made on the specimens prepared for the thermal diffusivity measurements are shown in figure 3. The contraction factor along the grain can be represented by $1-0.70(1-\mathrm{Z})^{4}$. The contraction factors in the radial and tangential directions can be represented by $1-0.64(1-Z)^{3}$ and $1-0.45(1-Z)^{3 / 2}$. The lowest mass fraction $(Z)$ obtained was 0.23 for the specimens charred at $750^{\circ} \mathrm{C}$.

\section{Absorptivity and Emissivity}

The emissivity is assumed to be equal to the absorptivity in the model. A value of 0.8 was taken to apply to the un-charred wood and a value of 1.0 after the mass retention fraction at the surface dropped to 0.9 . The initial value was based on a comparison of the initial rate of temperature rise of a blackened and un-blackened piece of Douglas fir suddenly exposed to a gas fired radiant panel.

\section{MODEL VERIFICATION}

The heat release rate and the heat of combustion were measured in the Cone calorimeter [5] using a $100 \mathrm{~mm}$ by $100 \mathrm{~mm}$ by $19 \mathrm{~mm}$ Douglas fir specimen oriented vertically and exposed to a radiant flux of $25 \mathrm{~kW} / \mathrm{m}^{2}$. The test was conducted in an adequate supply of air with ambient oxygen concentration. The rear surface of the specimen was in contact with an inert ceramic insulating blanket. The heat release rate calculated from 


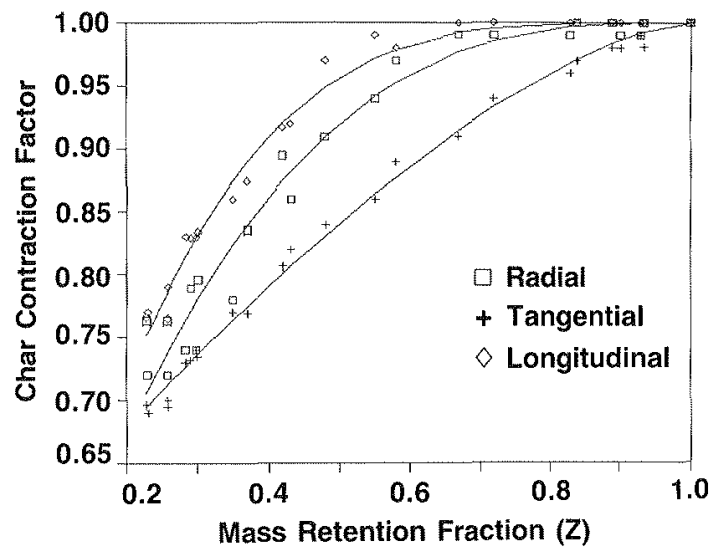

FIGURE 3. Char contraction factors.

the model is compared with this measurement in Figure 4 . The first peak in the calculated curve occurs at approximately the same time and has approximately the same amplitude as that in the measured curve. The minimums have similar amplitudes but are shifted considerably in time, resulting in a difference of nearly 50

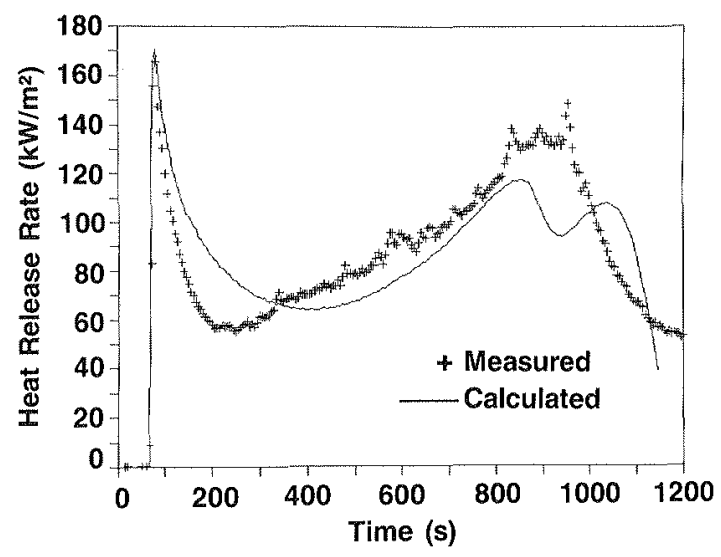

FIGURE 4. Comparison of calculated and measured heat release rate. 
percent in the calculated and measured heat release rate for a brief period. However, the average heat release rate over the whole burning period is essentially the same for both curves. There is a dip in the calculated second peak. This dip does not occur in the calculated heat release rates contributed by the individual chemical components of the wood. The dip in the composite curve is due to the differences in their individual time scales. This dip is not apparent in the measured curve. This discrepancy suggests the need for better kinetic data on the chemical components as they actually exist in the wood. The agreement between the calculated and measured heat release rate is not as good at the higher incident radiant fluxes. This may be due to changes in the thermal properties at the higher temperatures associated with these fluxes. Figure 5 shows good agreement between the calculated and measured heats of combustion in the first part of the burning period. There is a significant departure of up to 25 percent near the end.

\section{CONCLUSIONS}

The thermal diffusivity of Douglas fir and its char is nearly independent of temperature and mass retention fraction at least for temperatures up to $550^{\circ} \mathrm{C}$ and mass retention fractions of 0.3 and above with a value of approximately $2.1 \times 10^{-7} \mathrm{~m}^{2} / \mathrm{s}$. Using property data obtained on Douglas fir it has been possible to calculate the heat release rate of a $19 \mathrm{~mm}$ thick oven-dry vertical specimen exposed to an external radiant flux of $25 \mathrm{~kW} / \mathrm{m}^{2}$. The calculations are in rough agreement with the measurements in the Cone calorimeter. However, this agreement does not extend to the higher incident fluxes. There is a need for incorporating more physics and chemistry into the model and for better property data particularly at the higher temperatures.

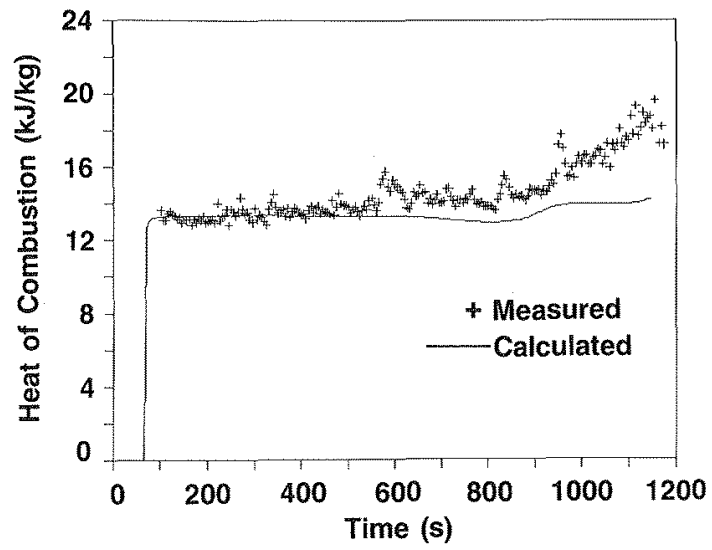

FIGURE 5. Comparison of calculated and measured heat of combustion. 


\section{REFERENCES}

1. Parker, W.J., "Prediction of the Heat Release Rate of Wood," Fire Safety Science-Proceedings of the First International Symposium, pp. $207-216,1985$.

2. Atreya, A., "pyrolysis, Ignition and Fire Spread on Horizontal Surfaces of Wood," PhD Thesis, Harvard University, May 1983.

3. Parker, W.J., "Determination of the Input Data for a Model of the Heat Release Rate of Wood," International Symposium on Mathematical Modeling of Fires and Related Test Methods, Sponsored by ASTM, New Orleans, pp. 105-115, Dec. 1986.

4. Parker, W.J, and LeVan, S.L., "Kinetic Properties of the Components of Douglas-Fir and the Heat of Combustion of their Volatile Pyrolysis Products," (to be submitted to Wood Fiber Science).

5. Babrauskas, V., "Development of the Cone Calorimeter - A Bench Scale Heat Release Rate Apparatus Based on Oxygen Consumption, "NBSIR 82 2611, Nat. Bur. Stand. (U.S.), Nov. 1982.

6. Dunlap, F., "The Specific Heat of Wood," U.S. Dep. Agr. Bu11. No. 110, Washington D.C., 1912.

7. Koch, P., "Specific Heat of Oven Dry Spruce Pine Wood and Bark," Wood Sci., 1: pp. 203-214, 1969.

8. Weast, R.C., Editor, Handbook of Chemistry and Physics, 57th Ed., pp. D158-D159, 1976-1977.

9. Susott, R. A., "Heat of Pre-ignition of Three Wood Fuels Used in Wildlife Modeling Research, " Research Note INT-342, Intermountain Forest and Range Experimental Station, Ogden, UT 84401, Sept 1984.

10. Carslaw, H.S, and Jaeger, J.C., Conduction of Heat in Solids, 2nd edition, p. 102, oxford University Press, 1959.

11.Tye, R.P., Desjarlais, A.O. and Singer, J.M., "Thermophysical Properties of Pittsburgh Seam Coal, "High Temperatures-High Pressures, 13: pp. 57-68, 1981.

12. Evans, D.D. and Emmons, H.W., "Combustion of Wood Charcoal," Fire Research, 1: pp. $57-66,1977$.

13. Maclean, J.D., "Thermal Conductivity of Wood," Heating. Piping and Air Conditioning, 13: pp. $380-391,1941$.

\section{NOMENCLATURE}

A pre-exponential factor $(1 / \mathrm{s})$

C specific heat $(\mathrm{kJ} / \mathrm{kg} / \mathrm{K})$

$\mathrm{C}_{c}$ specific heat of char $(\mathrm{kJ} / \mathrm{kg} / \mathrm{K})$

$\mathrm{C}_{\mathrm{w}}$ specific heat of wood $(\mathrm{kJ} / \mathrm{kg} / \mathrm{K})$

$\mathrm{K}$ thermal conductivity $(\mathrm{KW} / \mathrm{m} / \mathrm{K})$

$\ell$ thickness of specimen

$M$ moisture content (percent)

R gas constant ( $\mathrm{kCal} / \mathrm{mole} / \mathrm{K}$ )

$S$ specific gravity

$t$ time $(s)$ temperature (C)

specimen center temperature (C)

$\theta-\mathrm{T}_{\mathrm{M}}$

distance from surface (m)

defined by equation 10

mass/original mass

residual value of $z$ for char

thermal diffusivity $\left(\mathrm{in}^{2} / \mathrm{s}\right)$

average surface temperature 